\title{
Diálogos possíveis entre a Logoterapia e o judaísmo
}

\author{
Possible dialogues between Logotherapy and Judaism \\ Posibles diálogos entre Logoterapia y Judaísmo
}

Recebido: 18/04/2021 | Revisado: 23/05/2021 | Aceito: 13/05/2021 | Publicado: 01/06/2021

Levi Sales Viana Soares

ORCID: https://orcid.org/0000-0001-9101-6937

Universidade de Fortaleza, Brasil

E-mail: levisvsoares@hotmail.com

Angélica Yolanda Bueno Bejarano Vale de Medeiros

ORCID: https://orcid.org/0000-0001-9061-4476

Universidade Federal Fluminense, Brasil

E-mail: angelicaflow@gmail.com

\begin{abstract}
Resumo
A obra de Viktor Frankl é atravessada por temáticas ligadas à espiritualidade. Muito disto se deu em decorrência da experiência do autor nos campos de concentração da Alemanha Nazista, por sua condição de judeu. Também é notório que a prática religiosa judaica acompanharia o autor durante toda vida. Assim, este trabalho tem por objetivo analisar possíveis aspectos comuns entre a Logoterapia e o judaísmo, tanto no caráter religioso como cultural deste último, além da contribuição para a ciência da Psicologia. Trata-se de um estudo reflexivo e descritivo a partir de uma revisão da literatura nacional e internacional dos últimos cinco anos e com base nos livros de Viktor Frankl. Para tanto, foram investigados aspectos biográficos do autor, assim como elementos teóricos da Logoterapia ligados mais intimamente à questão da religiosidade e da espiritualidade. O diálogo com o judaísmo se deu orientado por importantes obras desta religião, onde se buscou correspondências com aspectos teóricos da Logoterapia. Por fim, constatou-se a existência de diversos pontos de convergência, os quais poderão ser melhor compreendidos em pesquisas futuras sobre o tema. Para Logoterapia, o trabalho possui importância ímpar para sua compreensão epistemológica e para a prática clínica, na medida em que se abordou questões relativas a técnicas.
\end{abstract}

Palavras-chave: Logoterapia; Judaísmo; Religiosidade.

\begin{abstract}
The work of Viktor Frankl is incessantly crossed by themes linked to human spirituality. Of course, much of this was due to the author's experience in the concentration camps of Nazi Germany, experienced as a Jew. Moreover, it is well known that Jewish religious practice would accompany the author until his last days. In this sense, this paper aims at analyzing possible common aspects between the Therapy of Viktor Frankl and Judaism, both in the religious and cultural character of the latter. This was done through a methodology of bibliographic review on the subject. In order to do so, biographical aspects of the author were investigated, as well as theoretical elements of Logotherapy linked more closely to the question of religiosity and spirituality, in order to familiarize the reader with the theme. Dialogue with Judaism was guided by important works of this religion, where correspondence was sought for the theoretical aspects of Logotherapy. Finally, there were several points of convergence, which could be better understood in future researches on the subject.
\end{abstract}

Keywords: Logoteraphy; Judaism; Religiosity.

\section{Resumen}

El trabajo de Viktor Frankl está atravesado por temas relacionados con la espiritualidad. Gran parte de esto se debió a la experiencia del autor en los campos de concentración de la Alemania nazi, debido a su condición de judío. También es notorio que la práctica religiosa judía acompañaría al autor durante toda su vida. Así, este trabajo tiene como objetivo analizar posibles aspectos comunes entre la Logoterapia y el judaísmo, tanto en el carácter religioso como cultural de este último, además del aporte a la ciencia de la Psicología. Se trata de un estudio reflexivo y descriptivo a partir de una revisión de la literatura nacional e internacional de los últimos cinco años y basado en los libros de Viktor Frankl. Para ello, se investigaron aspectos biográficos del autor, así como elementos teóricos de la Logoterapia más vinculados al tema de la religiosidad y la espiritualidad. El diálogo con el judaísmo estuvo guiado por importantes obras de esta religión, que buscó correspondencia con aspectos teóricos de la Logoterapia. Finalmente, se encontró que existen varios puntos de convergencia, que se pueden entender mejor en futuras investigaciones sobre el tema. Para la Logoterapia, el trabajo tiene una importancia inigualable por su comprensión epistemológica y para la práctica clínica, en la medida en que se abordan cuestiones relacionadas con las técnicas.

Palabras clave: Logoterapia; Judaísmo; Religiosidad. 


\section{Introdução}

Um dos elementos centrais na vida e, conseqüentemente, obra de Viktor Frankl é sua raiz judaica. Esta condição foi para o autor não apenas reflexo de costumes e uma prática religiosa, mas um marco ao longo de sua trajetória.

Foi justamente por ser judeu que Viktor Frankl conheceu o terror dos campos de concentração e, através desta experiência, pôde pôr a prova as teses básicas de sua Logoterapia, cuja aplicação e difusão tomou como o sentido de sua vida.

Viktor Frankl nasceu e criou-se em um lar judaico, tendo as influências religiosas de seu pai muito cedo em sua vida. Inúmeros episódios podem ser citados para confirmar a presença deste aspecto religioso na vida do autor, estejam eles em sua vida pessoal, intelectual ou profissional.

O autor vivenciou provavelmente uma das épocas mais árduas para o povo judeu. Afinal, a primeira metade do século XX foi marcada por um crescimento vertiginoso do anti-semitismo na Europa, especialmente no Império Austro-Húngaro. O continente ainda se redesenhava após a primeira guerra, o que gerava um clima crescente de incerteza.

Foi nesse contexto que Viktor Frankl viveu sua juventude e viu despertar sua intelectualidade. Viena foi ambiente propício para isto, dada a efervescência cultural que aflorava na cidade. Desde muito cedo, o autor teria contato com nomes célebres da psicologia, como Sigmund Freud e Alfred Adler.

É inegável perceber a presença judaica neste contexto intelectual, principalmente quando dirigimos nossa atenção aos teóricos da Psicologia, como é o caso dos dois últimos autores citados. Seria inclusive uma forte preocupação de Sigmund Freud distanciar a Psicanálise de ser considerada como uma ciência judaica (Gay, 2012).

O período de amadurecimento intelectual de Frankl foi marcado por seus rompimentos com a psicanálise freudiana e, posteriormente, com a psicologia individual de Alfred Adler. Foi após esse período que o autor viria a vivenciar ricas experiências profissionais; como foi o caso de seus trabalhos ${ }^{1}$ com adolescentes e no pavilhão dos suicidas (Aquino, 2014).

Em 1938 Adolf Hitler invade a Áustria, prenunciando o início da II Guerra Mundial. Com a eclosão do conflito, diversos intelectuais têm a oportunidade de deixar o país, dentre eles, o doutor Viktor Frankl. Contudo, esta chance não abrangia seus familiares. Seria exatamente um fragmento referente aos dez mandamentos, a lei judaica, encontrado por seu pai que manteria o criador da Logoterapia em Viena, com a convicção de que deveria se manter fiel a tradição e a seus antepassados $^{2}$. O futuro lhe garantiria a oportunidade de amenizar os sofrimentos de seu pai em seu leito de morte (Machado, 2013).

Exilado na Inglaterra, Sigmund Freud ironizaria em uma carta: "Que progressos estamos fazendo. Na idade média, teriam queimado a mim; hoje em dia, eles se contentam em queimar meus livros" (Gay, 2012, p. 536). Viktor Frankl não teve a mesma sorte, se é que podemos usar esta palavra. Talvez mais adequado seja afirmar que não traçou o mesmo destino.

Antes da experiência dos campos, Viktor Frankl assumiria o departamento de neurologia do Hospital Rotschild, cujo atendimento era voltado exclusivamente para judeus. Seria nesse local que ele salvaria diversos pacientes da morte por

\footnotetext{
${ }^{1}$ Estas foram duas experiências marcantes na carreira de Viktor Frankl. A primeira delas consistiu no auxílio a jovens com problemas psíquicos mediante atendimentos gratuitos. Neste contexto, em 1930 organizaria um atendimento voltado especificamente para a distribuição dos boletins e "o resultado foi que, pela primeira vez depois de muitos anos, não se registrou nenhum suicídio entre os alunos" (Frankl, 2010, pp. 81); fato este que lhe renderia visibilidade internacional. Mais tarde, entre 1933 e 1937, Viktor Frankl dirigiria o pavilhão dos suicidas no Hospital Psiquiátrico Am Steinhof, ocasião em que relata que "não menos de três mil pacientes passavam pelas minhas mãos por ano" (Frank1, 2010, pp. 87).

${ }^{2}$ Trata-se de um episódio bastante significativo. Consciente do inevitável destino que o aguardava nos campos, Viktor Frankl receberia um visto que lhe possibilitaria emigrar aos Estados Unidos. Esta oportunidade, contudo, não se estendia aos seus pais. Imerso em dúvida a respeito deste dilema, Viktor Frank1 seria surpreendido por seu pai certo dia ao chegar em casa: havia sobre a mesa um pequeno pedaço de mármore.

Questionado, seu pai indicaria que aquele era uma parte das tábuas dos 10 mandamentos de uma sinagoga que fora queimada recentemente. Este fragmento pertencia especificamente ao $5^{\circ}$ mandamento: Honra teu pai e tua mãe, para que se prolonguem teus dias na terra. Esta seria uma experiência fundamental para que Viktor Frankl decidisse ficar junto aos seus pais e enfrentasse o martírio dos campos (Frankl, 2010).
} 
eutanásia ${ }^{3}$. Neste mesmo período, casa-se com Tilly, sua primeira esposa.

Em setembro de 1942 se iniciaria o martírio nos campos de concentração. As passagens por Theresienstadt, Auschwitz, Kaufering III e Türkheim (Estes dois últimos como subcampos de Dachan) são caracterizadas por experiências intimamente ligadas à natureza humana. Foi nestes locais que, por ser judeu, Frankl vivenciaria diretamente a essência de seu pensamento.

Um episódio ocorrido em uma de suas passagens pelos campos é bem emblemática: "Ao entrar no campo, foram-lhe arrebatados todos os seus pertences, deram-lhe uma roupa velha e um prisioneiro já morto na câmara de gás. Ao pôr a mão no bolso, encontra uma oração escrita em hebraico, era o Shemá Yisrael" (Aquino, 2014, p. 20).

Nos campos, Viktor Frankl vivencia experiências religiosas, como quando se depara com trecho de cântico dos cânticos ao se recordar de sua esposa, e ensaia diversas intervenções "logoterápicas", como quando utiliza o humor para enfrentar as adversidades. Sua liberdade viria em 1945, tendo enfrentado a morte e escapado da solução final em Auschwitz (Frankl, 2012).

Viktor Frankl ficaria marcado como um autor que transitou entre os domínios da filosofia, da psicologia e da teologia, sempre cruzando fronteiras estabelecendo raízes nestes territórios. Tal qual o povo judeu, Viktor Frankl foi estrangeiro em seu percurso intelectual.

O autor sintetizaria: "Estou convencido de que as palavras milenares de Isaías - eis o que diz o vosso Deus: consolai o meu povo, consolai-o - conservam ainda hoje plena validade: mas não apenas em geral, e sim muito especial e diretamente para o médico" (Frankl, 2016, p. 389).

Neste pequeno resgate, fica perceptível o peso do judaísmo na trajetória de Viktor Frankl. Desta forma, o presente trabalho tem como finalidade investigar as influências da religião e cultura judaicas na obra do autor, buscando compreender até que ponto esta crença atravessa sua compreensão acerca da espiritualidade humana.

\section{Metodologia}

Trata-se de um estudo teorico reflexivo e descritivo dos possíveis aspectos comuns entre a Logoterapia e o judaísmo. "A pesquisa descritiva exige do investigador uma série de informações sobre o que deseja pesquisar. Esse tipo de estudo pretende descrever os fatos e fenômenos de determinada realidade" (Triviños, 1987, como citado em Gerhardt \& Silveira, 2009, p. 37).

Este estudo baseou-se em uma-revisão da literatura nacional e internacional dos últimos cinco anos e com base nos livros de Viktor Frankl, foram investigados a princípio aspectos biográficos do autor, assim como elementos teóricos da Logoterapia ligados mais intimamente à questão da religiosidade e da espiritualidade, com a finalidade de familiarizar o leitor com a temática. O diálogo para com o judaísmo se deu orientado por importantes obras desta religião, onde se buscou correspondências para com aspectos teóricos da Logoterapia.

A análise e a própria discussão orbita em torno destas premissas, principalmente por partir da hipótese de que pode existir uma importância do contexto sócio-cultural judaico na obra de Viktor Frankl, assim como possívies interlocuções entre esses dois campos.

\footnotetext{
${ }^{3}$ Este foi um programa implementado por Adolf Hitler através de um decreto de 1939, que consistia basicamente na eliminação sistemática de doentes mentais e outros incuráveis. Assim, o decreto foi cumprido inicialmente com os doentes mentais e "entre dezembro de 1939 e agosto de 1941 , cerca de 50 mil alemães foram mortos com monóxido de carbono em instituições cujas salas de execução eram disfarçadas exatamente como seriam depois em Auschwitz - como salas de duchas e banhos" (Arendt, 1999, pp.124).
} 


\section{Resultados e Discussão}

\subsection{Logoterapia, Espiritualidade e Religiosidade}

A partir da análise da literatura foram desenvolvidas duas categorias a serem discutidas: Logoterapia, espiritualidade e religiosidade. Além disto, precisamos ter em mente que abordar aspectos epistemológicos é tratar diretamente de questões clínicas, na medida em que os conceitos trabalhados implicam diretamente na prática terapêutica, como é o caso da noção de humor. Posto isto, iniciemos a discussão.

Ao ser questionado pelo teólogo e diplomata judeu Pinchas Lápide se havia rezado nos Campos de Concentração, o criador da Logoterapia responde categoricamente: “Eu posso apenas perguntar de volta: E onde não?” (Frankl \& Lapide, 2013, p. 150). Isto nos mostra o quanto a prática religiosa é, de certa forma, indissociável da vida e obra de Viktor Frankl.

Quem sabe por isso mesmo este empreendimento não passe na verdade de um esforço acadêmico para compreender aquilo que é impossível de ser tratado separadamente: a religiosidade de um homem e sua figura pública. Afinal, este divórcio somente é possível do ponto de vista teórico- epistemológico, jamais no prático.

De toda forma, o que podemos extrair dessa resposta é que a religiosidade acompanhou Viktor Frankl não apenas em momentos críticos, mas ao longo de toda a sua vida. Não à toa, em sua autobiografia, o criador da Logoterapia remonta suas primeiras lembranças da infância a temas religiosos (Frankl, 2010).

As experiências religiosas entrelaçaram-se aos questionamentos existenciais ao longo de sua mocidade. Podemos ver, por exemplo, no episódio ${ }^{4}$ onde o autor trava um embate socrático com seu professor acerca da essência da existência (Bulka, 1998), a profundidade dos aspectos filosóficos e teológicos ali implicados. Certamente um prenúncio do que seria o empreendimento de toda uma vida para o autor.

Muito de sua obra seria dedicada a responder a questão ali levantada: Qual seria, afinal, o sentido da vida? Ou, posto de outra forma, para quê o sentido da vida?

É com esta premissa de que a existência deve ter um sentido que o autor ratificará seu interesse não nos "porquês", mas "perante quem" este sentido se estabelece. Perante a sociedade, perante a própria consciência, perante o cônjuge... a resposta é dada pelo paciente, embora saibamos que, na visão pessoal de Viktor Frankl, o “perante quem” se refere sempre em última instância a Deus ${ }^{5}$ (Frankl \& Lapide, 2013; Dias et al., 2020).

Outro ponto bastante frutífero do diálogo é quando Viktor Frankl é questionado acerca de como Auschwitz influiria na crença daqueles que por lá passaram. Lapide pergunta-se nas entrelinhas se a experiência dos campos não minaria a crença dos homens em vez de fortalecê-la.

Viktor Frankl atesta: uma fé que se desfaz nestas situações, via de regra, não é uma fé genuína. Admite que apesar de não possuir dados quantitativos, em seu íntimo pôde perceber que mais pessoas readquiriram e fortaleceram sua fé nos campos de concentração do que o contrário. Por isso Viktor Frankl conclui aludindo a "uma crença apesar de Auschwitz” (Frankl \& Lapide, 2013, p. 84).

Dialogando com Pinchas Lápide, Viktor Frankl também se depara com uma questão típica do ateísmo moderno, porém, tão antiga quanto a própria filosofia: Se Deus é bom, porque permite o mal? Em outras palavras, Auschwitz não atestaria justamente a falha na justiça de Deus, ou mesmo sua inexistência?

\footnotetext{
${ }^{4}$ Viktor Frankl, à época com aproximadamente 13 anos, questionaria um professor que afirmou categoricamente que a vida nada mais era que um processo de combustão e oxidação: "Professor, se isto é assim, que sentido tem a vida?" (Miguez, 2014, pp. 18).

${ }^{5}$ Em seu diálogo com Pinchas Lapide, Viktor Frankl pontua: “Quando um homem, mesmo o ateísta, tem monólogos muito íntimos consigo mesmo, e íntimo significa com absoluta sinceridade e com absoluta franqueza, ou seja, sem nenhuma consideração - quando nós realmente não enganamos a nós mesmos, então nós temos o direito de chamar de Deus quem ou aquilo a que nos dirigimos aqui" (Frankl \& Lapide, 2013, pp. 113) e a seguir "E eu acredito que isto não seja apenas uma realidade, mas sim uma entidade suprapessoal, uma sobrepessoa, que no mínimo precisa ser uma pessoa. O que há de errado nisto" (Frankl \& Lapide, 2013, pp. 114)
} 
Ambos os autores concordam que esta é, na verdade uma falsa questão. Isto reside no fato de que os horrores praticados nos campos foram perpetuados por mãos humanas, e não pela vontade de Deus. Atribuir tais atos a Deus, além de uma ofensa ao Mesmo, seria retirar a responsabilidade dos homens.

Ainda neste raciocínio, Viktor Frankl compreende que se Deus é pensado pelos homens, nada mais natural que apresente determinadas atribuições que o tornam próximo ao homem, isto é, antropomórfico ${ }^{6}$. Provavelmente, entra em questão aqui a dita imagem e semelhança, tão presente na cultura judaico-cristã. De toda forma, o autor não considera esta visão como um problema, já que a própria ciência também possui suas raízes antropomórficas. Ainda na esteira de suas convicções, o autor também se distância da noção de uma religião universal e do pluralismo religioso, na medida em que enxerga justamente o crescimento de uma religiosidade de caráter pessoal, onde cada pessoa desenvolve a sua maneira e própria de se dirigir a Deus (Frankl \& Lapide, 2013).

Diferentemente de Sigmund Freud, Viktor Frankl não estabelece uma nova esfera psíquica, até então inexistente para a ciência da época. Se a Psicanálise revelou ao mundo a dimensão psíquica do Inconsciente, a Logoterapia centrou esforços em trazer para a psicoterapia a espiritualidade do homem. Esta dimensão, embora muito difundida em diversas outras áreas ficava às margens, quando não era simplesmente ignorada do trabalho psicoterápico 7 .

A partir de seus estudos, Sigmund Freud passou a esquadrinhar a religiosidade humana em aspectos psicodinâmicos. Desta forma, passou a compreendê-la enquanto a expressão de aspectos inconscientes, algo similar ao que ocorre com um sintoma para a teoria psicanalítica. É o que vemos no seguinte trecho de uma de suas obras mais famosas e controversas:

Afinal de contas, um sentimento só poderá ser fonte de energia se ele próprio for expressão de uma necessidade intensa. A derivação das necessidades religiosas, a partir do desemparo do bebê e do anseio pelo pai que aquela necessidade desperta, parece-me incontrovertível, desde que, em particular, o sentimento não seja simplesmente prolongado a partir dos dias da infância, mas permanentemente sustentado pelo medo do poder superior do Destino. Não consigo pensar em nenhuma necessidade da infância tão intensa quanto a da proteção de um pai. Dessa maneira, o papel desempenhado pelo sentimento oceânico, que poderia buscar algo como a restauração do narcisismo ilimitado, é deslocado de um lugar em primeiro plano. A origem da atitude religiosa pode ser remontada, em linhas muito claras, até o sentimento de desemparo infantil (Freud, 1996i, pp. 80, 81).

Ora, a religiosidade encarada desta forma não deixa ao psicoterapeuta outra opção que não seja a enfrentá-la enquanto resistência. Foi este tipo de raciocínio que orientou psicólogos a tratar a espiritualidade não como algo genuinamente humano, mas como um campo de ação da vida pulsional como o ódio ao pai existente num complexo de inferioridade. Isto termina por implicar numa visão reduzida do homem, que não pode considerar sua totalidade justamente por ignorar a dimensão da liberdade humana (Pulino \& Rosa, 2020).

Não se aborda, nesta visão, a religiosidade em seu aspecto mais profundo e sublime, mas em sua suposta função frente a um desiquilíbrio psíquico. A religiosidade passava a se equiparar a um sintoma que deveria ser extirpado ao longo do processo psicoterápico (Frankl \& Lapide, 2013).

Em completo desacordo, Viktor Frankl aborda a espiritualidade não como mais um elemento relacionado ao jogo de forças do psiquismo, mas como algo concernente à própria constituição humana; conforme esclarece em "A presença ignorada de Deus" (Frankl, 2017). Estava aí estabelecida a noção tridimensional do homem enquanto ser biológico, psicológico e

\footnotetext{
${ }^{6}$ Conceito de Deus orientado para a humanidade, isto é, pensado a partir do homem e de suas características e, por isto, enviesado para a crítica ateísta.

${ }^{7} \mathrm{O}$ tema é controverso, mas em geral é bastante clara a hostilidade da psicanálise frente a religiosidade, o que nos impede de considerar a questão como uma antipatia pessoal de Sigmund Freud em relação a mesma. Isto fica perceptível na obra de outros autores psicanalistas, como no caso de Jaques Lacan, um de seus sucessores: "Se a religião triunfar, como é bem provável - e aqui falo da verdadeira religião, só existe uma verdadeira - se a religião triunfar, será sinal que a psicanálise fracassou” (Lacan, 1975, pp.6).
} 
noético ${ }^{8}$ (Frankl, 2017). Portanto, nesta última dimensão estabelece-se a noção de liberdade da Logoterapia, na medida em que o homem não é mais prisioneiro de sua condição biológica, psíquica ou social. Afinal, lembremos que uma concepção mais ampla do ser humano que abarca diversas dimensões e inclui em seu cerne a capacidade de articular uma linguagem própria e simbolizar aponta para a necessidade da adoção de um sentido mais abrangente da saúde, que não se restringe aos aspectos biológicos, psicológicos e sociais (Dias et al., 2020).

De forma sucinta, a dimensão noética está intimamente ligada às premissas antropológicas da Logoterapia, como colocado anteriormente. Portanto, esta dimensão refere-se à autoconsciência e, consequentemente, à transcendência do homem; chegando-se ao que podemos chamar por visão integral de homem. Viktor Frankl considera que é justamente na transcendência de si que "o homem se eleva sobre seu ser psicofísico, deixa o plano do somático e do psíquico e entra no espaço humano propriamente dito, o qual é constituído por uma nova dimensão, a dimensão poética, a dimensão do espiritual" (Frankl, 1976, p. 44).

Desta maneira, Viktor Frankl propunha o fim do cisma entre a Psicologia e a Religião no plano teórico, apresentando como equivocado desejo de explicar a espiritualidade pelas vias psicológicas. Restava estabelecer o lugar desta questão dentro do contexto da psicoterapia.

Viktor Frankl foi extremamente cuidadoso ao abordar o tema, na medida em que demarca uma fronteira entre a abordagem da espiritualidade no setting clínico e a confissão de fé. Não cabe, como se sabe desde o nascimento da psicologia, convencer ou guiar o paciente acerca de determinado credo, por mais que este seja verdadeiro e cristalino para o terapeuta. Frankl alude muito mais a um incentivo da busca, orientada pela singularidade de cada pessoa. Em suas palavras:

\begin{abstract}
Note-se, entretanto, o seguinte: por mais longe que esteja o empenho e as preocupações da religião, na sua primeira intenção, o saneamento anímico ou a prevenção de doenças, o que certamente sucede é que ela, per effectum - e não per intentionem! - tem uma repercussão psico-higiênica e efetivamente terapêutica, porquanto permite ao homem uma segurança e uma ancoragem incomparáveis, que em parte alguma poderia encontrar: a segurança e a ancoragem na transcendência, no Absoluto. Pois bem, do lado da psicoterapia também poderíamos salientar um efeito lateral análogo e espontâneo, que corrobora o que acabamos de dizer. Refiro- me a casos, sem duvida raríssimos, mas que não sem dúvida também os mais felizes para o paciente e para o medico, em que aquele, no decurso do tratamento psicoterápico, reencontra as fontes, ha muito enterradas, de uma fé originária, que tinha reprimido e tornado inconsciente. Mas, ainda assim possa ocorrer, nunca isso poderia constituir o legitimo escopo do medico: com efeito, se o medico fosse ao encontro do paciente no mesmo plano confessional e baseando-se numa espécie de união pessoal para orientar o tratamento - então já de antemão, não estaria de modo algum tratando o paciente como médico (Frankl, 2016, pp. 367, 368).
\end{abstract}

Resumidamente, cabe ao psicoterapeuta pôr em movimento a espiritualidade sem definir os rumos de seu fluxo. Afinal, a experiência transcendente não se limita a uma religião institucional em particular. Foi basicamente desta forma que Viktor Frankl constatou os benefícios psicológicos da vivência religiosa no homem, na medida em que esta se relaciona intimamente com o questionamento acerca do sentido da vida ou, mais propriamente, do suprassentido ${ }^{9}$ (Frankl, 2011; 2016).

Estes benefícios, segundo Viktor Frankl, vêm não da religiosidade propriamente dita, mas de seus efeitos na busca do sentido. Lembremos aqui da conceituação, afinal, "o Sentido da Vida pode ser entendido como a percepção cognitiva e afetiva de valores, os valores representam o que há de maior importância e significado pessoal” (Medeiros et al., 2020, p.12). Nos limites da psicoterapia, nem sempre é possível alterar as contingências externas, ou a realidade na qual o paciente está inserido e que gera seu sofrimento. Trata-se de auxiliá-lo no processo de dar sentido ao sofrimento.

\footnotetext{
${ }^{8}$ Optamos aqui pela terminologia noética ao invés de espiritual para evitar quaisquer equívocos que o termo em português possa gerar, tendo-se em vista seu cunho religioso no português. Cabe destacar a origem grega da etimologia noûs, referente a espírito enquanto forma mais elevada de conhecimento. Outra terminologia também utilizada é noológico.

${ }^{9}$ Por suprassentido, Viktor Frankl compreende o sentido último da vida. Consequentemente, atesta que "não conseguimos relacionar-nos com esse suprassentido em solo puramente racional, mas, apenas, em solo existencial, por meio do todo de nosso ser, isto é, por meio da fé” (Frankl, 2011, pp. 181).
} 
Portanto, uma pessoa capaz de enxergar o sentido de uma tragédia sofre menos, mesmo que não seja capaz de alterar a realidade propriamente dita. Nas palavras do autor, é "a partir do mundo transcendente que o sofrimento humano obtém sua derradeira dotação de sentido, que ele obtém aquele sentido transcendente que se projeta para além de toda capacidade humana de apreensão" (Frankl, 2012, p. 146).

E é justamente pelo caráter pessoal do sentido que uma crença imposta de fora não pode estabelecê-lo. Fazê-lo seria destruir a liberdade humana e cair no viés determinista que Viktor Frankl tanto denunciou. Afinal, o que define o sentido é justamente o aspecto pessoal aplicado a uma situação irrepetível da vida já que "o homem toma posição a cada instante de sua existência" (Frankl, 2012, p. 95).

Assim, tendo exposto o lugar da espiritualidade e da religiosidade no pensamento de Viktor Frankl, podemos adentrar nas possíveis interlocuções entre a Logoterapia e o judaísmo.

\subsection{Judaísmo e Logoterapia}

O judaísmo, uma das religiões monoteístas mais antigas do mundo, a primeira das três grandes religiões abraâmicas, teve seu surgimento entre o povo hebreu há mais de três mil anos. Considera-se como marco de seu nascimento a figura de Abraão. Os principais textos sagrados do judaísmo são compostos pelo o Tanach (A Bíblia hebraica, composta pelo Torá, Neviim e Ctuvim), o Talmude e o Zohar.

Existem também diferentes pensamentos religiosos judaicos que não consistem propriamente numa unidade, embora existam traços comuns a todos. Sua influência é extremamente marcante no contexto da civilização ocidental até a atualidade.

No decorrer de 3500 anos de história judaica, uma história dispersada através de uma geografia universal muito ampla, já que a maioria dos judeus viveu no exílio durante a maior parte de sua história, o povo judeu formou uma comunidade de memória, uma memória que transcendeu as fronteiras geográficas e concentrou-se na manutenção de uma identidade judaica distinta em torno dos ciclos eternos sagrados do tempo santo. Essa identidade judaica pode melhor ser caracterizada pela herança textual sagrada, uma herança lida continuamentee em voz alta a cada sétimo dia, no Shabat, em ciclos eternos sagrados de tempo santo, onde quer que vivessem (Elior, 2014, p. 49).

Assim, diversos acontecimentos históricos marcariam a tradição, fé e cultura judaicas. É o que se atesta, por exemplo, ao longo do período exílio e escravidão no Egito, narrado no livro do Êxodo. Assim, uma condição física também atravessa o espírito, na medida em que sufoca a autoexpressão e a autodeterminação deste povo ${ }^{10}$. Não à toa, "um famoso ditado chassídico declara: É mais fácil tirar o judeu do exílio que tirar o exílio do judeu” (Steinsaltz, 2010, p.2).

Compreender determinados aspectos do judaísmo evidencia uma das fontes de inspiração de Viktor Frankl, na medida em que sua obra traz traços claros deste berço cultural. Como já foi pontuado, é público que Viktor Frankl foi até seus últimos dias um judeu devoto.

Uma das primeiras passagens do Zohar, o Livro do Esplendor, é bastante categórica: "Está escrito, como uma rosa entre espinhos" (Laitman, 2012, p. 41). A rosa em questão é o povo de Israel. Algo bastante próximo da visão da Logoterapia acerca do sofrimento, quando Viktor Frankl conceitua o homo patiens ${ }^{l l}$ (Frankl, 2010), o homem que sofre tal qual rosa entre espinhos.

\footnotetext{
${ }^{10}$ Por isto é completamente compreensível a leitura que, muitas vezes, a liberdade transforma o homem num escravo sem amo. Em outras palavras, os judeus quiseram ao longo deste processo se libertar genuinamente dos fardos da escravidão e do cativeiro, porém, "tendo passado a vida inteira como escravos, não podiam simplesmente jogar fora a finidade que tinham desenvolvido em relação a seus feitores. Somente depois que a geração nascida no cativeiro tinha falecido, o povo judeu pôde (...) constituir uma nação de homens livres" (Ezra como citado em Steinsaltz, 2010, pp.1)

${ }^{11}$ Trata-se de um conceito recorrente na obra do autor, utilizado para enfatizar a questão do sentido do sofrimento. "Ao homo sapiens, nós contrapomos o homo patiens. Ao imperativo sapere aude, contrapomos um outro: pati aude - ousa sofrer" (Frankl, 2012, pp. 142).
} 
Neste sentido, o Talmude convida a uma atitude positiva frente ao sofrimento, uma "abordagem caminha junto a visão da Logoterapia de sofrimento. A Logoterapia e o Talmude operam de dimensões diferentes, mas existe um paralelismo em suas respectivas atitudes frente ao sofrimento" (Bulka, 1998, p. 137). Isto fica claramente visível quando Viktor Frankl considera que

(...) a vida só adquire forma e figura com as marteladas que o destino lhe dá quando o sofrimento a põe ao rubro. O sentido do destino que um homem sofre reside, em primeiro lugar, em ser pelo homem configurado - se possível; e, em segundo lugar, em ser suportado - se necessário. $\mathrm{O}$ sofrimento, como a necessidade, o destino e a morte, faz parte da vida. Nenhum destes elementos se podem separar da vida sem lhe destruir o sentido. Privar a vida da necessidade e da morte, do destino e do sofrimento, seria como tirar-lhe a configuração, a forma (Frankl, 2016, p. 198).

É este o lugar do sofrimento na visão de homem da Logoterapia, algo constituinte da existência. Trata-se da forma como o homem se submete frente ao irremediável, onde sempre subsiste uma possibilidade de sentido. Para o judaísmo, é uma oportunidade de retificação do homem perante Deus; para a Logoterapia, um chamado a dar sentido ao sofrimento.

Desta forma, a tradição judaica atesta que "em lugar de escravos movendo-se sob a coação de um porrete chamado sofrimento, podemos transformar nosso caminho de sofrimento" (Laitman, 2012, p.50) ${ }^{12}$. É, portanto, uma inferência cristalina que, através da abertura ao transcendente, possibilitada pela dimensão noética, o homem arrebenta os grilhões dos tormentos de sua existência. Esta noção de liberdade é bastante clara na conceituação de Viktor Frankl acerca da tese do otimismo trágico $^{13}$.

Nosso coração é a soma de nossos desejos egoístas e o pequeno ponto em seu interior é parte do desejo espiritual e altruísta implantado das Alturas pelo próprio Criador. É nossa tarefa nutrir esse embrião de um desejo espiritual, a tal ponto que este (e não nossa natureza egoísta) venha a determinar todas as nossas aspirações. Ao mesmo tempo, o desejo egoísta do coração se renderá, se contrairá, murchará e diminuirá (Laitman, 2012, p. 46).

Esta noção presente no Zohar também se aproxima da conceituação de Viktor Frankl acerca do homem, mais especificamente nas esferas fisiológica e psicológica associadas aos desejos egoístas, e a esfera noética, onde habita o transcendente e a sede metafísica do homem. É neste sentido que podemos apontar a importância da dimensão noética, na medida em que proporciona a transcendência, que "remete a algo que se lança para além do homem" (Frankl, 2012, p. 112).

Esta idéia de transcedência, inclusive, nos remete uma outra semelhança em relação a Logoterapia e o judaísmo: a existência de um sentido laetente e oculto em nossas vidas. Isto vem precisamente da noção de que "ambos compreendem que o ser humano, ao morrer, precisa deixar o mundo melhor do que o encontrou" (Aquino \& Cruz, 2020, P. 998), tendo-se em vista principalmente o caráter único e irrepetível da vida humana.

Afinal, Viktor Frankl destaca que é exatamente no outro que o homem transforma-se em si mesmo; "ele é completamente homem exatamente na proporção em que ele não objetiva a si mesmo ou sua auto-realização" (Frankl \& Lapide, 2013, p. 96).

\footnotetext{
${ }^{12}$ Esta colocação, inclusive, fornece um contraponto à questão do ocasionalismo judaico, onde se compreende que de alguma forma nosso destino estaria traçado de antemão pela vontade divina. Embora esta seja uma parte importante da cosmovisão judaica, ela não exclui o caráter de liberdade do homem (Laitman, 2012).

${ }^{13}$ A tese do otimismo trágico está intimamente ligada à chamada tríade trágica: o sofrimento, a culpa e a morte. Frente a estes três aspectos, a Logoterapia propõe uma postura corajosa ao transmutar os mesmos em algo positivo: o sofrimento pode se tornar uma realização, a culpa num convite para a mudança e a morte um chamado para uma vida mais responsável. Decorre-se disto que "a Logoterapia é muito mais, uma abordagem otimista da vida, ao ensinar que não há nenhum aspecto da negativo da existência que não possa ser transmutado em conquistas positivas, em tudo a depender da atitude que se venha a assumir" (Frankl, 2011,pp. 94).
} 
Mais do que isto, Frankl destaca que "por trás do superego do ser humano não está o eu de um super-homem, mas atrás da consciência está o tu de Deus" (Frankl, 2017, p. 55). É a este Deus, em última instância, que se dirige a consciência em seus solilóquios mais íntimos.

Aqui, delimitam-se a teologia e a psicologia. Justamente por isto que Viktor Frankl se apresenta completamente avesso à idéia de uma psicoterapia que envolva um credo, onde o "perante quem" não seja respondido pelo paciente. Afinal, "se para ele fosse tal, é porque já seria crente" (Frankl, 2016, p. 369). Por isto, a Logoterapia situa-se aquém da questão da fé religiosa, situando-se mais próxima de um conceito de fé mais geral.

Ao psicoterapeuta cabe apontar esta possibilidade. Viktor Frankl enxergava "a religião como um fenômeno humano que precisava ser visto de forma positiva na situação clínica, ao mesmo tempo que insistia que a Logoterapia não impõe religiosidade no paciente" (Bulka, 1998, pp. 133, 134).

Trata-se, como já abordado anteriormente de uma delimitação necessária entre a direção de almas pastoral e médica. Neste sentido, destaca- se que "a religião é um fenômeno que se dá no homem, no paciente; um fenômeno entre outros muitos que à Logoterapia se depara. Para a Logoterapia, a religião é, e só pode ser, um objeto - não, porém, uma posição" (Frankl, 2016, p. 366).

Estabelecida esta fronteira, podemos adentrar nas temáticas onde podem residir interlocuções entre a Logoterapia e o judaísmo. Embora não existam muitas referências diretas, é possível apontar aspectos em comum entre estas áreas.

Antes disto, devemos pontuar o fato de que a obscuridade de Viktor Frankl no meio judeu não deve ser tratada como acaso. Por isto, ele chegaria a relatar que, durante uma participação em um evento numa Universidade Hebraica de Jerusalém "senti-me mais solitário do que quando estive no deserto" (Frankl como citado em Bulka, 1998, p. 84).

A princípio, é importante destacar que existe um claro paralelo entre a visão da Logoterapia da liberdade enquanto submetida ao destino ${ }^{14}$, em seu aspecto determinista em relação ao físico, psicológico e sociológico; com a afirmação talmúdica de que tudo está escrito, mas o direito de escolha ainda é garantido e preservado (Bulka, 1998).

Um ponto bastante nevrálgico se refere à consolação. "Foi sobretudo na arte de consolar que o judaísmo deve ter influenciado de forma marcante esse pensador" (Aquino, 2014, p. 27). É claro nas escrituras que o povo de Israel muitas vezes decidiu entre a resignação frente a revolta na injustiça. Deus não apenas consola seus filhos, como o fez quando Isaac perdeu seu pai, como constantemente envia seus profetas para consolar seu povo, quando poderia incitar-lhes a uma rebelião.

Mais além, a questão do consolo é algo extremamente enraizado na tradição judaica, na medida em que se trata de uma manifestação divina realizada pelos homens, tendo por base a empatia para com o outro. É uma prática obrigatória para os judeus principalmente em situações de luto (Fridlin, 2006).

Tecendo um paralelo, em muitos casos, a prática clínica confronta o logoterapeuta com ocasiões onde já não cabe ao paciente modificar a realidade propriamente dita de seu destino, mas resignar-se em sofrê-lo. Por isto coloca-se no âmbito da Logoterapia que "o último auxílio é a consolação que eu presto quando consigo tornar visível, apesar de um grande sofrimento que não cede, a última possibilidade, aliás, a mais alta, de encontrar um sentido para a vida" (Frank1, 2016, pp. 389, 340).

Um outro ponto de consonância se refere à questão da morte. Conforme exposto anteriormente, Viktor Frankl encara a finitude enquanto um convite à responsabilidade, afinal, somente quando confrontado com a morte que o homem encontra sentido para agir. Trata-se de um dos elementos destacado na Tese do Otimismo Trágico.

É precisamente o fato de um limite derradeiro da vida, ou seja, de um limite derradeiro da possibilidade de ação, que nos obriga a aproveitar o tempo e a não deixar sem utilização uma ocasião propícia para a ação. Portanto, é justamente a morte que, então, empresta sentido à vida e à nossa existência como algo único (Frankl, 2012, p. 19).

${ }^{14}$ Cabe aqui uma colocação bastante pertinente em relação a dualidade liberdade destino, tendo-se em vista que, como bem coloca o criador da Logoterapia, existe uma diferença entre homem que é livre de e o homem que é livre para (Frank1, 2016). 
Neste ponto é visível uma aproximação com a noção judaica presente no Talmude que "aborda a noção inerente de que a morte, devidamente compreendida, pode ser uma força de vida vital” (Bulka, 1998, p. 114). Percebemos ai a importância da dimensão noética, na medida em que se percebe o papel distinto da transcendência do homem no processo, afinal, "a morte está mais perto e mais longe de você na medida em que a você está próximo ou distante de si” (Bulka, 1998, p. 114).

Em um diálogo de um famoso sábio, foi-lhe colocada a seguinte questão: "Por acaso pode o homem saber o dia de sua morte?". Ao que respondeu: "Então esta é mais uma razão para que ele se arrependa hoje, para que não morra amanhã e para que sua vida não seja desperdiçada em meio a repetição". É neste sentido que a morte depara o homem com a responsabilidade e o convida uma postura de coragem, tal qual o salmista que cantou diante da morte (Bulka, 1998, p. 113).

É o que se infere ao longo da obra de Viktor Frankl, quando o autor destaca que todo homem é capaz de dar sentido a sua vida até o seu último suspiro. A finitude, portanto, não é apenas uma característica essencial da vida humana, mas também constitutiva desse sentido, na medida em que o mesmo está fundado em seu caráter irreversível (Frankl, 2012).

Por fim, podemos destacar a possível presença do humor judaico, tão marcante na Logoterapia. Este tipo de humor singularizase por sua tendência à autodepreciação, à autocrítica e à autocomiseração. Alguns estudos apontam que o humor judaico se configura enquanto uma forma de se defender das perseguições sofridas ao longo do tempo (Pitliuk, 2015).

Algo muito familiar a nós, brasileiros. Trata-se da capacidade de arrancar riso de nossos próprios dramas, fazendo com que assim nossas tragédias se tornem mais suportáveis. Nas palavras do pai da Logoterapia, trata-se de compreender que

O humor é um fenômeno humano que, por suas características, possibilita ao homem o distanciar-se de qualquer coisa e de quem quer que seja, e de si mesmo também, consequentemente, para se fazer inteiro senhor de sua pessoa. E, sempre que aplicamos a intenção paradoxal, nosso desejo e empenho está precisamente em mobilizar este poder essencialmente humano do distanciamento. Aliás, bem pode dizer-se que, se isto acontece com o humor, conseguimos já ultrapassar aquela advertência de Konrad Lorenz, que nos acusa de ainda não tomarmos o humor suficientemente a sério (Frankl, 2016, p. 402).

Não por acaso, como citado acima, a centralidade do riso na Logoterapia é visualizada de forma clara na técnica conhecida por Intenção Paradoxal ${ }^{15}$ (Frankl, 2016). Portanto, é um sinal bastante animador quando o paciente consegue fazer piadas e anedotas frente a seu próprio sofrimento, indicando que o mesmo já é capaz de auto distanciar-se de suas tragédias. Em outras palavras

O doente aprenderá paulatinamente a colocar-se cada vez mais acima do sintoma, e este tipo de humorismo em que o introduzimos e em que, para dizer toda a verdade, o ensaiamos, simplifica-lhe o problema tanto como toda a espécie de humor, que afinal facilita ao homem o pôr-se acima de uma situação, para dominá-la (Frankl, 2016, p. 284).

Em suma, as correlações entre a logoterapia e o judaísmo não se esgotam nos aspectos abordados. Trata-se portanto de perceber que afinal a questão do sentido na Logoterapia encontra ecos na máxima talmúdica que ensina que a busca pelo sentido derradeiro não é uma simples pergunta, mas sim uma resposta encontra (Bulka, 1998).

\footnotetext{
${ }^{15}$ Esta é uma técnica bastante utilizada na Logoterapia, principalmente em casos de ansiedade e fobias. Ela assenta-se na constatação de que o medo produz aquilo que tememos, ou seja, o mecanismo da ansiedade antecipatória. Compreendendo isto, o psicoterapeuta solicita que seu paciente intencione precisamente aquilo que teme minimamente. Com a inversão da atitude, o medo dá lugar a um desejo paradoxal, diminuindo a ansiedade gerada na situação em questão. Desta maneira, o indivíduo passa a distanciar-se de seu próprio sofrimento. Uma das formas indicadas para o manejo desta técnica é justamente a utilização do humor autodepreciativo, convidando o paciente a rir de si mesmo e de seu sintoma (Frankl, 2016).
} 


\section{Considerações Finais}

Percebemos, ao longo do exposto, alguns pontos de convergência claramente significativos entre a Logoterapia e o judaísmo. Contudo, é importante destacar que esta convergência se deve mais a uma influência da religiosidade de Viktor Frankl em sua vida do que a uma expressão direta de sua fé em seus trabalhos.

É cristalino, como foi abordado, que o judaísmo teve um papel crucial na existência de Viktor Frankl que, afinal, padeceu os horrores dos campos de concentração devido sua origem. Evidentemente, não se pode imaginar a Logoterapia dissociada desta experiência.

Além disto, os elementos apresentados decorrentes da vida privada do autor também atestam a centralidade do judaísmo para Viktor Frankl. As próprias experiências do autor parecem ter papel essencial na sua compreensão acerca da religiosidade.

Entretanto, é digno de nota que são relativamente poucas as referências diretas à esta religiosidade em seus escritos e a tímida difusão da Logoterapia junto aos círculos judaicos, conforme atestado anteriormente. Contudo, poucas são as justificativas encontradas para esta questão (Bulka, 1998).

A própria obra de Viktor Frankl, que muitas vezes transita por diferentes territórios epistemológicos como a teologia, a filosofia, a psicologia e a psiquiatria permite uma correlação com o povo judeu, muitas vezes estrangeiro, apátrida e errante entre diferentes terras na sua busca pela terra prometida. Afinal, o autor também foi estrangeiro nestes terrenos, sendo encarado muitas vezes com a mesma desconfiança que cercava seu povo.

Esta desconfiança, todavia, apresenta-se muitas vezes como uma compreensão equivocada acerca da Logoterapia, na medida em que se atesta seu zelo em relação a liberdade de seus pacientes e a importância da religiosidade para os mesmos.

Contrariamente ao que é posto pela Psicanálise, na Logoterapia trata-se de compreender o aspecto mais sublime da religiosidade e seus benefícios para os homens, constatados através de sua prática clínica e nas pesquisas conduzidas por diversos autores. Alguns autores inclusive indicam a importância da religiosidade para o próprio processo de promoção da saúde dos indivíduos, o que ocorre através da já colocada ligação com o sentido e com a afirmação da vida (Dias et al., 2020).

Diferentemente das críticas de autores como Rollo May, que apontam um autoritarismo na prática clínica de Viktor Frankl, este último é extremamente claro ao destacar que não se trata de imposições, mas de auxiliar seus pacientes na busca pelo sentido (Bulka, 1998).

Não que o judaísmo tenha sido a única fonte de Viktor Frankl, afinal, a influência de Max Scheller nos mostra o contrário. Outrossim, "a logoterapia como sistema aberto a todas as formas de pensamento pode se sustentar sem o reforço do pensamento judeu" (Bulka, 1998, pp. 81, 82). Afinal, o autor foi extremamente cuidadoso ao destacar que a Logoterapia se configurava mais como um complemento que uma abordagem (Frankl, 2016).

Mais do que isto, é importante também destacar que a obra de Viktor Frankl encontrou eco em diversos sistemas religiosos, como se pode constatar na audiência solicitada pelo Sumo Pontífice Paulo VI e o pai da logoterapia, na qual foi reconhecida a importância de sua obra não apenas para a Igreja Católica, mas para toda a humanidade (Frankl, 2010).

Por fim, uma citação do Talmude diz que "aquele que salva uma alma de Israel é como aquele que salvou o mundo inteiro" (Rodkinson, 1903, pp. 31). E este foi de fato uma constante ao longo da vida e obra de Viktor Frankl, seja em sua estadia nos campos de concentração ou em seu trabalho clínico.

Tratou-se aqui de compreender o papel da formação e fé judaica de Viktor Frankl em seus escritos. Conforme foi exposto, muitas das experiências do autor foram marcadas diretamente por sua fé e diversos aspectos teóricos atestam correlações bastante consideráveis. 
Este trabalho, portanto, buscou mostrar-se consonante com sua proposta, na medida em que apresentou aspectos comuns entre a Logoterapia e o judaísmo, atestando a hipótese de que existem traços afins entre estes dois terrenos. Pesquisas futuras poderão evidenciar de forma mais clara estes meandros.

Em suma, como conclui Pinchas Lápide acerca de Frankl:

Se o senhor que como um homem adulto sofreu o inferno do campo de concentração, ou, como a Bíblia diz, teve de beber o cálice do sofrimento até o fim e esteve em condições de sobreviver a isto sem ódio pela humanidade, então o senhor é a prova viva de Deus (Frankl \& Lapide, 2013, p. 115).

\section{Agradecimentos}

Agradecemos ao corpo docente da Especialização e Logoterapia da Faculdade Católica de Fortaleza (Seminário da Prainha), em especial na figura do professor Doutor Ivo Studart Pereira pelas contribuições ao trabalho e ao amigo Marcelo Barzilai, Rabino da Sinagoga Humanista Teshuvá de Curitiba pelas contribuições no tocante ao judaísmo.

\section{Referências}

Aquino, T. A. A. (2014). A presença não ignorada de Deus na obra de Viktor Frankl: articulações entre logoterapia e religião. Paulus.

Aquino, T. A. A., Cruz, J. S. (2020) Semelhanças e aproximações da mística judáica na obra de Viktor Frankl. Caminhos, Goiânia, 18(3).

Arendt, H. (1999). Eichmman em Jerusalém. Companhia das Letras.

Bíblia: Bíblia de Jerusalém. (1981). Paulinas.

Bulka, R. P. (1998 ). Work, love, suffering, and death: a jewishperspective through logoteraphy. Philosophical Library.

Dias, F. A., Pereira , E. R., Silva, R. M. C. R. A., \& Medeiros, A. Y. B. B. V. (2020). Spirituality and health: a critical thinking about the simbolical life. Research, Society and Development, 9(5), p. e52953113. https://doi.org/10.33448/rsd-v9i5.3113

Elior, R. (2014). A expressão da liberdade humana no misticismo judaico. Revista do Instituo Cultural Judaico Marc Chagall, 6(2), 49-76. https://seer.ufrgs.br/webmosaica/article/view/53256

Frankl, V. E. (1976). Psicoterapia: uma casuística para médicos. EPU.

Frankl, V. E. (2010). O que não está escrito nos meus livros: memórias. É Realizações.

Frankl, V. E. (2011). A vontade de sentido: fundamentos e aplicações da Logoterapia. Paulus.

Frankl, V. E. (2012). Logoterapia e análise existencial: textos de seis décadas. Forense Universitária.

Frankl, V. E. (2016). Psicoterapia e sentido da vida: fundamentos da logoterapia e análise existencial (6. ed.). Quadrante.

Frankl, V. E. (2017). A presença ignorada de Deus (18. ed.). Vozes.

Frankl, V. E., \& Lapide, P. (2013). A busca de Deus e questionamentos sobre o sentido. Vozes.

Freud, S. (1996i). O mal-estar na civilização. In S. Freud. Edição Standard das Obras Completas de Sigmund Freud (vol. 21). Imago. (Obra original publicada em 1930).

Fridlin (Org.), J. ( 2006). Minchá e Arvit: Com as leis de assistência aos enfermos. Chevra Kadisha Sociedade Cemitério Israelita de São Paulo.

Gay, P. (2012). Freud: uma vida para o nosso tempo (2nd ed.). Companhia das Letras.

Gerhardt, T. E., \& Silveira, D. T. (2009). Gerhardt, T. E., \& Silveira, D. T. (Orgs.). (2009). Métodos de pesquisa. Editora da UFRGS.

Lacan, J. E. (1975). Paruedans les Lettres de L'École freudienne de Paris [n. 16]. Conférence de presse au Centre culturel français, Rome, Paris.

Laitman, R. M. (2012). O Zohar: O livro do esplendor. Imago.

Machado, A. E. S. (2013). O papel de Deus na cura: segundo Viktor Frankl. Ideias \& Letras.

Medeiros , A. Y. B. B. V., Dias, F. A., Pereira, E. R., \& Silva, R. M. C. R. A. (2020). Psychological phases and meaning of life in times of social isolation due the COVID-19 pandemic a reflection in the light of Viktor Frankl. Research, Society and Development, 9(5), e122953331. https://doi.org/10.33448/rsdv9i5.3331

Miguez, E. M. (2014). Educação em busca de sentido: pedagogia inspirada em Viktor Frankl. Paulus. 
Research, Society and Development, v. 10, n. 6, e34710615176, 2021

(CC BY 4.0) | ISSN 2525-3409 | DOI: http://dx.doi.org/10.33448/rsd-v10i6.15176

Pereira, A. S., Shitsuka, D. M., Parreira, F. J. \& Shitsuka, R. (2018). Metodologia da pesquisa científica. Universidade Federal de Santa Maria, Núcleo de Tecnologia Educacional.

Pitliuk, M. (2015). Cócegas no cérebro. Morashá. http://www.morasha.com.br/arte-e-cultura/cocegas-no-cerebro.html

Pulino, L. H. C. Z., Rosa. G. M. O. (2020) O humano em Søren Kierkegaard e em Viktor Frankl. Memorandum, 37. https://doi.org/10.35699/16761669.2020 .6877

Rodkinson, M. L. (1903). Bablonian Talmud (vol. 1) (2a ed.). Boston New Talmud Publishing Compnay.

Steinsaltz, A. (2010). Uma Escravidão Chamada Liberdade. Chabad.org. 